\title{
Quantitative Analysis of Tridymite and Cristobalite Crystallized in Rice Husk Ash by Heating
}

\author{
Yasushi SHINOHARA* and Norihiko KOHYAMA
}

\author{
National Institute of Industrial Health, 6-21-1, Nagao, Tama-ku, Kawasaki 214-8585, Japan \\ Received January 17, 2004 and accepted February 17, 2004
}

\begin{abstract}
The quantities of two forms of crystalline silica, tridymite and cristobalite, in heated rice husk ash (RHA) samples were determined by X-ray diffraction (XRD) and chemical methods. Two RHA samples, containing $93 \% \mathrm{SiO}_{2}$ and $2-3 \% \mathrm{~K}_{2} \mathrm{O}$, were prepared from charcoaled rice husk products and heated to above $900^{\circ} \mathrm{C}$. The crystalline silica made up over $60-80 \%$ of the total silica in the heated RHA samples based on the XRD analysis. The crystalline phases in the two samples were somewhat different: The sample heated in the temperature range of 900 to $1,200^{\circ} \mathrm{C}$ contained 52-62\% cristobalite and 10-17\% tridymite, but the other sample heated at a comparable temperature, above $1,100^{\circ} \mathrm{C}$, contained $46-66 \%$ tridymite and $37-16 \%$ cristobalite. Based on a correlation of lower tridymite crystallization temperature with higher potassium content, it was concluded that higher potassium levels were responsible for this difference. The pyrophosphoric acid analysis did not give exact results in the evaluation of total crystalline silica content in these RHA samples. As the combustion of rice husk was considered to cover the demands for energy and silica resource in Asian countries, cristobalite and tridymite crystallized in RHA by burning of rice husk should be assessed precisely by XRD analysis and the airborne dust in relevant workplace be controlled.
\end{abstract}

Key words: Tridymite, Cristobalite, Crystalline silica, Amorphous silica, Rice husk ash, X-ray diffraction

\section{Introduction}

The most common form of crystalline silica found in workplaces is quartz, but cristobalite and tridymite are also present as the other forms of crystalline silica. Although tridymite and cristobalite are crystallized at $867-1,470^{\circ} \mathrm{C}$ and $1,470-1,727^{\circ} \mathrm{C}$, respectively, at atmospheric pressure ${ }^{1)}$, they continue to exist at room temperature. There is a claim, however, that an adequate amount of alkali ion is required as a flux or mineralizer for the crystallization of tridymite ${ }^{2)}$. Due to this constraint on the crystallization of tridymite, the occurrence of tridymite in workplaces may be restricted in some materials such as silica bricks that have been used for many years at high temperature. In heat-treated materials, cristobalite is a more common form of crystalline silica. In general, compared with quartz, little attention has been paid

*To whom correspondence should be addressed. for the recognition of tridymite and cristobalite due to their rarity and a lack of information.

Rice husk (or rice hull) is one of the major residues after rice production. It contains 13-29\% inorganic components, of which $87-97 \%$ is $\mathrm{SiO}_{2}$ (silica) ${ }^{3)}$ in an amorphous state. The use of silica from the residual rice husk has been a major concern of many researchers. Their approach may be classified into two categories: 1) purification or modification of rice husk to produce highly pure silicon and silica compounds ${ }^{3-6)}$,2) utilizations as an economic source of silica for the cement industry, lightweight construction products, abrasives and absorbents ${ }^{7,8)}$. In the latter category, rice husk is usually burnt to white ash to obtain and use the silica it contains.

Rice husk ash (RHA) can be obtained by burning or heating rice husk above $400-500^{\circ} \mathrm{C}$. The presence of amorphous silica, crystalline silica or both in RHA depends on the temperature of heating used in this process. Many studies have shown that RHA obtained at around $1,000^{\circ} \mathrm{C}$ contains a certain amount 
Table 1. Sample description of rice husk and rice husk ash used in this study

\begin{tabular}{|c|c|c|}
\hline $\begin{array}{l}\text { Sample name used } \\
\text { in this study }\end{array}$ & Sample description & Composition \\
\hline Rice husk & - & Organic (cellulose, pentosans, etc.) and inorganic (mostly amorphous silica) compounds ${ }^{* 1}$ \\
\hline $\begin{array}{l}\text { Charcoaled rice husk } \\
\quad(\mathrm{CRH})\end{array}$ & Original sample & Inorganic compounds ( $25 \%$ as residual ash after combustion at $450^{\circ} \mathrm{C}$ ) and carbon \\
\hline $\begin{array}{l}\text { Rice husk ash } \\
\text { (RHA) }\end{array}$ & $\begin{array}{l}\text { Combustion of } \mathrm{CRH} \\
\text { at } 450^{\circ} \mathrm{C}\end{array}$ & Amorphous silica /(silicate) $\left(<93 \%\right.$ as $\left.\mathrm{SiO}_{2}\right)$ and other compounds \\
\hline $\begin{array}{l}\text { Leached (washed) } \\
\text { RHA }\end{array}$ & $\begin{array}{l}\text { Acid leached and/or } \\
\text { water washed RHA }\end{array}$ & Amorphous silica /(silicate) $\left(<97 \%\right.$ as $\left.\mathrm{SiO}_{2}\right)$ and other compounds \\
\hline Heated RHA & $\begin{array}{l}\text { Heating of RHA } \\
\text { at } 700-1,350^{\circ} \mathrm{C}\end{array}$ & Crystalline silica (60-80\% tridymite and cristobalite) and amorphous silica/ (silicate)? \\
\hline
\end{tabular}

*1: after Juliano $(1985)^{7}$.

of tridymite and cristobalite ${ }^{3,6,8)}$. Although there are many studies dealing with the transformation of amorphous silica to tridymite and cristobalite at around $1,000^{\circ} \mathrm{C}^{9-11)}$, quite a few studies have examined the quantities and characteristics of the crystalline phase in heated silica ${ }^{11,12)}$.

A large amount of RHA is produced in Asia, notably in Southeast Asian countries, in each year by the combustion of rice husk in power generation plants or in open-field burning. The occurrence of cristobalite and tridymite in such RHA has been reported in some published literature ${ }^{8}$. A possible silicosis case was reported in workers who engaged in the packing and screening of RHA products ${ }^{13)}$. This observation implies that the risk of exposure to crystalline silica is higher in workers engaged in industries and farming operations dealing with RHA.

In this study, the presence and characteristic of crystalline silica in RHA samples heated at various temperatures were examined quantitatively by analyzing the crystalline silica content based on X-ray diffraction (XRD) and pyrophosphoric acid methods. By comparing the data obtained by these methods, we evaluated both methods in their effectiveness for analyzing samples containing tridymite and cristobalite.

\section{Materials and Methods}

Table 1 lists the terminology of the materials used in this study to clarify the composition of rice husk, RHA and heated RHA. Two commercial charcoaled rice husk samples were used in this study. One is a fragmented charcoal of rice husk that has been used for the improvement of soil fertility ("Kun-tan" (KT)). The other is a powdered charcoal rice husk product that has been used for a source material of glaze on pottery ("Momi-hai" (MH)). The production of these products probably involved combustion at low temperature and low oxygen conditions.

These charcoaled rice husk samples were combusted at about $450^{\circ} \mathrm{C}$ until almost the entire charcoal portion disappeared. After ashing, they were pulverized to a powder. After this preparation, these two RHA samples (KT-A and MH-A) were used in the following experiments.

Each 1-2 g RHA sample was put into a $10 \mathrm{ml}$ platinum crucible and heated in a muffle furnace from $500^{\circ} \mathrm{C}$ to 700 , $800,900,1,000,1,100,1,200$ and $1,350^{\circ} \mathrm{C}$ for 6 or $24 \mathrm{~h}$ at each temperature.

Chemical analyses of KT-A and MH-A were conducted for the major components by means of an X-ray fluorescence spectrometer (RIX-2000, Rigaku Co.). These RHA samples were heated at $110^{\circ} \mathrm{C}$ for a few hours, weighed precisely, and then made into fused glass beads using a high frequency bead sampler (TK-4200, Tokyo Kagaku Co.). A flux-tosample ratio of 5:1 was adopted for the bead using a spectroscopic-grade lithium tetraborate (Wako Pure Chemical Co.) for the flux. The bead samples of calibration standards were prepared in the same manner using the following standard materials: five clay samples of high silica composition (JRRM 101-105, Technical Association of Refractories, Japan), two quartz powders (JCRM R405 and R406, Ceramic Society of Japan), and three silicic rock standards (GJS JG-2, JR-3 and JCh-1, Geological Survey of Japan). The empirical matrix correction factor method was employed to make standard calibration curve. The measured data were processed using a software package in the spectrometer. Water and other volatile components were determined as ignition loss by a gravimetric analysis.

The crystalline phases of the heated RHA samples were identified and quantified by XRD analysis. A powder Xray diffractometer (RINT 2200, Rigaku Co.) equipped with 
a copper X-ray tube, counter graphite monochromator and scintillation detector was used. Qualitative search match analysis was made using the ICDD PDF-2 database. The content of each crystalline phase was determined by the metal substrate standard method ${ }^{14}$ for the sample consisting of particles smaller than $7 \mu \mathrm{m}$ in size, which was prepared by water elutriation method from the heated RHA sample. The calibration standard materials used for the XRD analysis were tridymite (NIOSH TY-27) ${ }^{15}$ ) and cristobalite (NIST SRM 1879). The integrated intensities of the peaks at $20.5^{\circ}$ (4.32 $\AA$ ) and $21.8^{\circ}(4.06 \AA)$ were used for the determination of tridymite and cristobalite, respectively. When the cristobalite peak at $21.8^{\circ}$ overlapped with the $21.6^{\circ}(4.10 \AA)$ peak of tridymite, the following equation was applied for the determination of cristobalite ${ }^{16,17)}$

$$
\frac{I_{21.6}+I_{21.8}}{I_{20.5}}=K \frac{I_{r, 21.8}^{C} X_{C}}{I_{r, 20.5}^{T} X_{T}}+\frac{I_{r, 21.6}^{T}}{I_{r, 20.5}^{T}}
$$

In this formula, $\mathrm{X}_{\mathrm{C}}$ and $\mathrm{X}_{\mathrm{T}}$ are the weight proportions of cristobalite and tridymite, respectively. The variables with the format such as $\mathrm{I}_{21.6}$ mean the integrated intensity of the peak at around the angle specified by the suffix. The following relative intensities of tridymite and cristobalite, which were normalized relative to the most intense peak of each phase, were experimentally obtained and used in the calculation, $I_{r, 20.5}^{T}=1.0, I_{r, 21.6}^{T}=0.9$ and $I_{r, 21.8}^{C}=1.0$. To determine the constant $\mathrm{K}$, which depends on the geometry of the XRD apparatus and the composition of cristobalite and tridymite, a 1:1 mixture of tridymite and cristobalite was prepared with the standard material. The diffraction pattern of this mixture was taken, and the intensities of the $20.5^{\circ}$ peak and overlapped peak at around $21.8^{\circ}$ were measured, then the constant was calculated.

A modified pyrophosphoric acid method ${ }^{18)}$ was conducted for "free silica" analysis to evaluate the total amounts of crystalline silica in the heated RHA samples. One-hundred $\mathrm{mg}$ of each sample consisting of particles smaller than 7 $\mu \mathrm{m}$ in size was used in the analysis.

\section{Results}

\section{Chemical composition of RHA samples}

Chemical compositions of the RHA samples (KT-A and MH-A) are shown in Table 2. Table 2 also shows the chemical compositions of these RHA samples treated with hydrochloric acid ( $\mathrm{HCl}$ ). Two RHA samples (KT-A and $\mathrm{MH}-\mathrm{A}$ ) contained about $93 \% \mathrm{SiO}_{2}$ and total $\mathrm{Al}_{2} \mathrm{O}_{3}, \mathrm{Fe}_{2} \mathrm{O}_{3}$ and $\mathrm{MgO}$ in KT-A was about $1 \%$. In addition, it is a characteristic feature of these RHA samples to contain a fairly high concentration
Table 2. Chemical compositions of rice husk ash samples (KT-A and MH-A) and their samples leached with hydrochloric acid (KT-AL and MH-AL)

\begin{tabular}{lrrrr}
\hline & KT-A & KT-AL & MH-A & MH-AL \\
\hline $\mathrm{SiO}_{2}$ & 92.95 & 96.94 & 93.26 & 96.52 \\
$\mathrm{TiO}_{2}$ & 0.02 & 0.02 & 0.01 & 0.01 \\
$\mathrm{Al}_{2} \mathrm{O}_{3}$ & 0.31 & 0.13 & 0.09 & 0.04 \\
$\mathrm{Fe}_{2} \mathrm{O}_{3}$ & 0.26 & 0.02 & 0.17 & 0.02 \\
$\mathrm{MnO}$ & 0.12 & 0.01 & 0.12 & 0.03 \\
$\mathrm{MgO}$ & 0.55 & 0.04 & 0.23 & 0.03 \\
$\mathrm{CaO}$ & 0.53 & 0.05 & 0.45 & 0.07 \\
$\mathrm{Na}{ }_{2} \mathrm{O}$ & 0.08 & 0.03 & 0.08 & 0.02 \\
$\mathrm{~K}_{2} \mathrm{O}$ & 2.06 & 0.49 & 2.95 & 0.69 \\
$\mathrm{Ig.} \mathrm{Loss}$ & 1.97 & n.d. & 1.98 & n.d. \\
\hline Total $(\%)$ & 98.86 & 97.72 & 99.33 & 97.42 \\
\hline
\end{tabular}

$\mathrm{Fe}_{2} \mathrm{O}_{3}$ : total iron as $\mathrm{Fe}_{2} \mathrm{O}_{3}$. n.d.: not determined.

of potassium about 2 to $3 \%$ as $\mathrm{K}_{2} \mathrm{O}$. After leaching with $\mathrm{HCl}$, the $\mathrm{SiO}_{2}$ content in these RHA samples increased to about $97 \%$ while other components except potassium decreased to almost below $0.1 \%$. The potassium remained at a slightly higher level of 0.49 and $0.69 \%$ as $\mathrm{K}_{2} \mathrm{O}$ for KT$\mathrm{AL}$ and $\mathrm{MH}-\mathrm{AL}$, respectively.

\section{Crystalline phases of heated RHA samples}

Representative XRD patterns of the RHA and heated RHA samples are shown in Fig. 1. The XRD patterns of the RHA samples (KT-A and MH-A) show a single diffuse band centered at around $21.6^{\circ}$ (Figs. 1-A and 1-F). This indicates that the silica in these materials was in an amorphous state. Although a weak peak of quartz was barely observed at $26.6^{\circ}$ in these materials, the quartz content was estimated to be almost negligible.

The XRD patterns of the heated RHA samples show the presence of crystalline silica phases. After $6 \mathrm{~h}$ of heating, cristobalite was observed above $800^{\circ} \mathrm{C}$ for the KT sample (Fig. 1-B) and above $700^{\circ} \mathrm{C}$ for the $\mathrm{MH}$ sample (not shown). A weak peak at $20.5^{\circ}$ accompanied with a strong cristobalite peak at $21.8^{\circ}$ and an additional weak peak at $27.5^{\circ}$ can be seen in Figs. 1-C and 1-G (indicated by arrows). These weak peaks were identified as tridymite. The other peaks seen in Figs. 1-C and 1-G coincided with those of cristobalite (ICDD PDF No.39-1425). The XRD patterns of Figs. 1-E and $1-\mathrm{H}$ to $1-\mathrm{K}$ show three characteristic peaks of tridymite at $20.5^{\circ}, 21.6^{\circ}$ and $23.3^{\circ}$ in addition to the $21.8^{\circ}$ peak of cristobalite. The polymorph of tridymite was identified as a monoclinic form by the comparison of the peaks at 20 $40^{\circ}$ with those of the ICDD data of tridymite. 

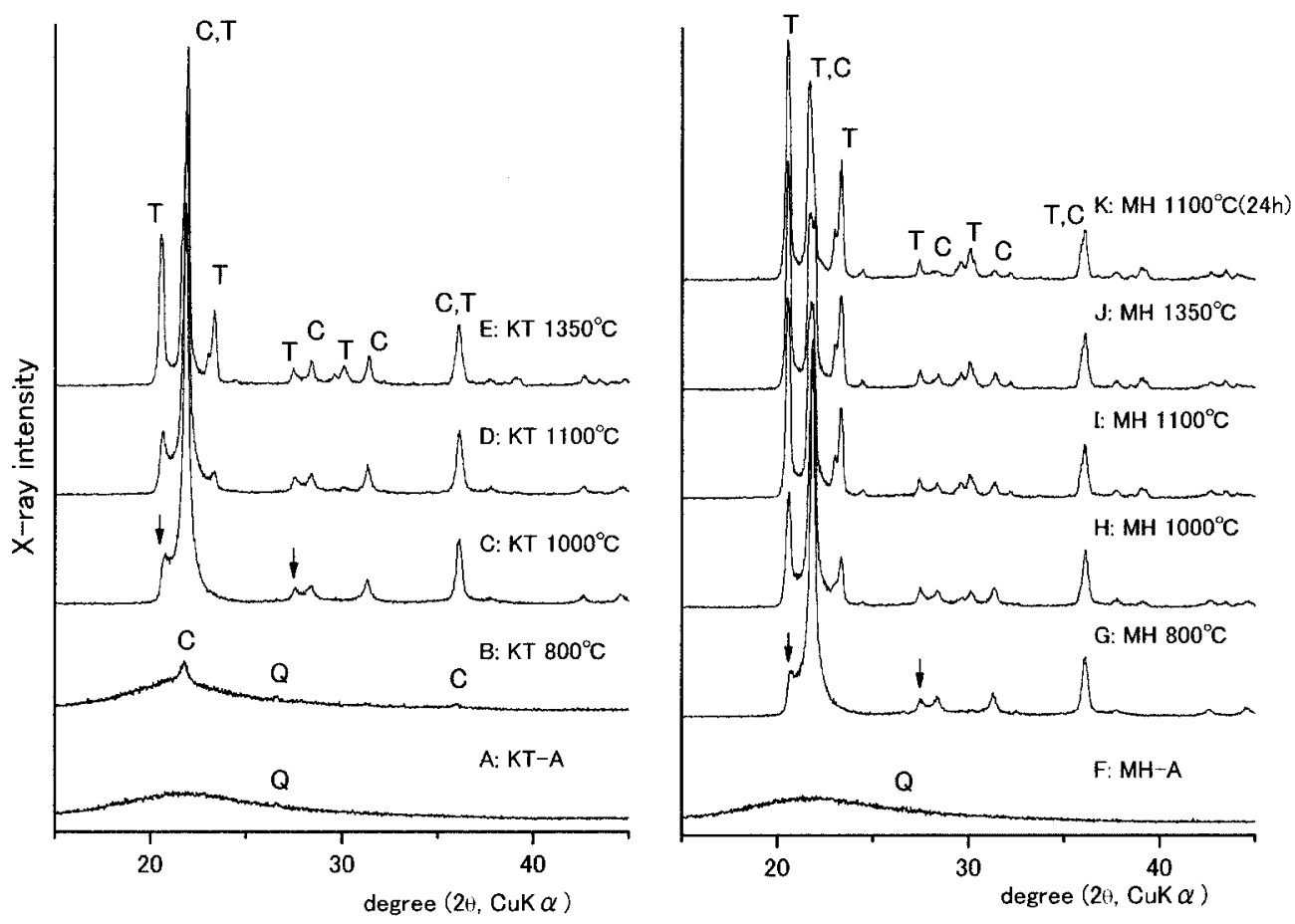

Fig. 1. X-ray diffraction patterns of rice husk ash samples after heating at various temperatures. Symbols C, T and Q: peak position of cristobalite, tridymite and quartz, respectively.

Quantification of the contents of tridymite and cristobalite by XRD

The contents of tridymite and cristobalite crystallized in heated RHA samples at various temperatures between $700^{\circ} \mathrm{C}$ and $1,350^{\circ} \mathrm{C}$ are summarized in Table 3 and Fig. 2. After heating from $900^{\circ} \mathrm{C}$ to $1,200^{\circ} \mathrm{C}$ for $6 \mathrm{~h}$, KT-A contained $52-62 \%$ cristobalite and $10-17 \%$ tridymite. After heating at $1,350^{\circ} \mathrm{C}$ for $6 \mathrm{~h}$, KT-A contained $31 \%$ cristobalite and $52 \%$ tridymite. On the other hand, MH-A contained 53\% cristobalite and $10-12 \%$ tridymite after heating at 800 $900^{\circ} \mathrm{C}$. The content of cristobalite in $\mathrm{MH}-\mathrm{A}$ decreased to $28-38 \%$ after heating from $1,000^{\circ} \mathrm{C}$ to $1,200^{\circ} \mathrm{C}$, and to $16 \%$ after heating to $1,350^{\circ} \mathrm{C}$, whereas the content of tridymite increased to $58 \%$ after heating at $1,100^{\circ} \mathrm{C}$ and remained at $46-66 \%$ after heating to $1,350^{\circ} \mathrm{C}$.

The total crystalline silica content in the two RHA samples increased from 60 to $80 \%$ with increasing heating temperature. The total crystalline silica content was 74 $85 \%$ after $24 \mathrm{~h}$ of heating, as shown in the MH samples, higher than those treated to only $6 \mathrm{~h}$ of heating. The tridymite content was $68-78 \%$ at $1,000-1,200^{\circ} \mathrm{C}$ after $24 \mathrm{~h}$ of heating, also higher than for the $6 \mathrm{~h}$ heating.

These results showed that these heated RHA samples start the transformation from amorphous silica to cristobalite accompanied with a small amount of tridymite. At higher temperatures or after long heating time, the proportion of tridymite increases and becomes the main phase, whereas the proportion of cristobalite decreases.

Silica phases crystallized in leached RHA samples by heating

Since the RHA samples contained a fairly higher amount of potassium, the effect of potassium content on the crystallization of silica was examined. Potassium ions in the RHA samples (KT-A and MH-A) were mostly eliminated by leaching the samples with $\mathrm{HCl}$ and/or washing with pure water. The chemical compositions of these leached and/or washed samples were characterized by a higher content of $\mathrm{SiO}_{2}$ and lower $\mathrm{K}_{2} \mathrm{O}$ than those of KT-A and MH-A as described previously. These leached and/or washed samples were also heated to various temperatures. Table 3 shows the contents of cristobalite and tridymite for two acid leached samples (MHL1350 and KTL1350) and two water washed samples (KTW 1000 and KTW1200). After heating above $1,200^{\circ} \mathrm{C}$, these samples contained mostly cristobalite with a small amount of tridymite.

Silica phases in heated RHA samples prepared by different grinding methods

Although the RHA samples were gently pulverized into 
Table 3. Heating conditions of rice husk and rice husk ash samples and their contents of crystalline silica and free silica

\begin{tabular}{|c|c|c|c|c|c|c|}
\hline \multirow{2}{*}{$\begin{array}{l}\text { Sample } \\
\text { name }\end{array}$} & \multicolumn{2}{|c|}{ Heating condition } & \multicolumn{3}{|c|}{ Crystalline silica by XRD } & \multirow{2}{*}{$\begin{array}{c}\text { Free silica* } \\
(\%)\end{array}$} \\
\hline & Temp $\left({ }^{\circ} \mathrm{C}\right)$ & Time (h) & Tridymite & Cristobalite & Total $(\%)$ & \\
\hline KT-A & 450 & 22 & - & - & $\operatorname{tr} .($ Quartz) & 84 \\
\hline KT 800 & 800 & 6 & - & $<5$ & $<5$ & 43 \\
\hline KT 900 & 900 & 6 & 10 & 52 & 62 & \\
\hline KT 1000 & 1,000 & 6 & 11 & 57 & 68 & \\
\hline KT 1100 & 1,100 & 6 & 17 & 53 & 70 & \\
\hline KT 1200 & 1,200 & 6 & 16 & 62 & 78 & \\
\hline KT 1200 (24 h) & 1,200 & 24 & 50 & 26 & 76 & 56 \\
\hline KT 1350 & 1,350 & 6 & 52 & 31 & 83 & \\
\hline MH-A & 450 & 6 & - & - & tr.(Quartz) & 28 \\
\hline MH 700 & 700 & 6 & - & $<5$ & $<5$ & \\
\hline MH 800 & 800 & 6 & 10 & 53 & 63 & \\
\hline MH 900 & 900 & 6 & 12 & 53 & 65 & \\
\hline MH 900 (24 h) & 900 & 24 & 29 & 44 & 74 & \\
\hline MH 1000 & 1,000 & 6 & 34 & 38 & 72 & \\
\hline MH 1000 (24 h) & 1,000 & 24 & 74 & 8 & 83 & 56 \\
\hline MH 1100 & 1,100 & 6 & 58 & 29 & 87 & \\
\hline MH 1100 (24 h) & 1,100 & 24 & 78 & 7 & 85 & 59 \\
\hline MH 1200 & 1,200 & 6 & 46 & 3 & 83 & \\
\hline MH 1200 (24 h) & 1,200 & 24 & 68 & 10 & 78 & 57 \\
\hline MH 1350 & 1,350 & 6 & 66 & 16 & 81 & 61 \\
\hline KTW $1000^{* 2}$ & 1,000 & 12 & - & - & - & 41 \\
\hline KTW $1200^{* 2}$ & 1,200 & 24 & - & 63 & 63 & 72 \\
\hline KTL $1350^{* 3}$ & 1,350 & 6 & 10 & 63 & 73 & 65 \\
\hline MHL $1350^{* 3}$ & 1,350 & 6 & 18 & 65 & 83 & 73 \\
\hline TY-27 & & & 100 & & 100 & 79 \\
\hline SRM 1879 & & & & 100 & 100 & 83 \\
\hline
\end{tabular}

*1: Free silica content by pyrophosphoric acid analysis. *2: Sample washed with water. *3: Sample leached with hydrochloric acid. -: not detected, tr. trace amount.

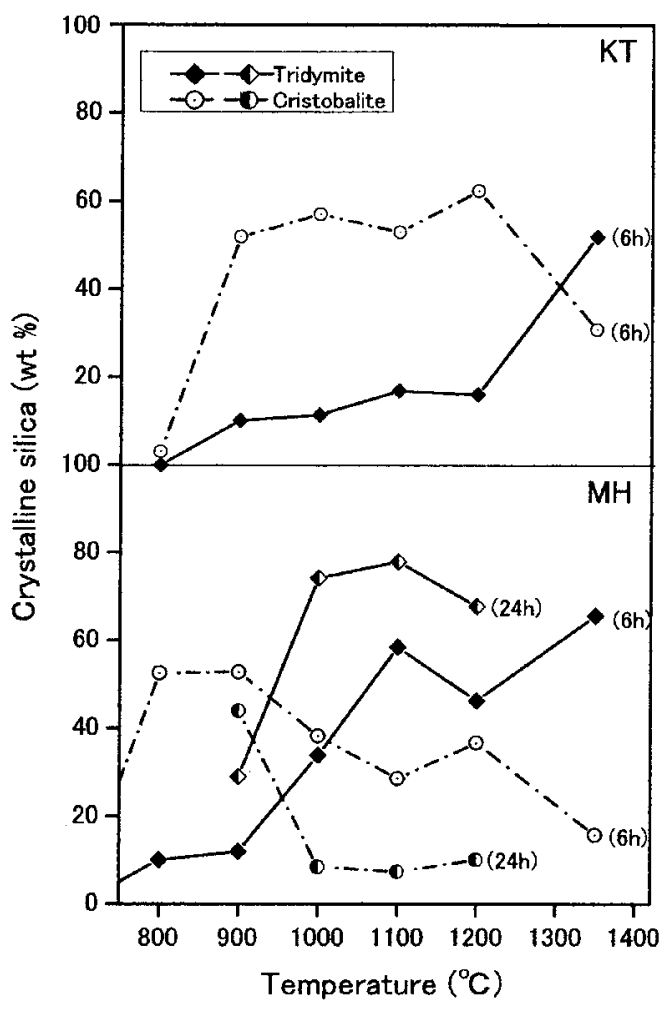

powders, one RHA sample (KT-A) retained the morphology of original rice husk after ashing. To examine the effect of grinding of the samples on crystallization of the silica phases, KT-A was prepared by two different grinding methods (fine grinding and gentle pulverization) and then heated for $24 \mathrm{~h}$ at $1,200^{\circ} \mathrm{C}$. Figure $3-\mathrm{A}$ shows the XRD pattern of a finely ground heated KT-A powder and Fig. 3-B shows that of a gently pulverized heated KT-A powder. As shown in Fig. 3 , tridymite and cristobalite were present in these samples. However, the peak intensity of each crystalline phase shows that the finely ground powder (Fig. 3-A) contained a higher tridymite content than that of the pulverized powder (Fig. 3-B), under the same heating conditions.

"Free silica” contents of RHA samples

Table 3 and Fig. 4 show free silica contents, which can be obtained by pyrophosphoric acid analysis, together with

Fig. 2. The amounts of cristobalite and tridymite formed in heated rice husk ash samples KT (after $6 \mathrm{~h}$ heating) and MH (after $6 \mathrm{~h}$ and 24 h heating). 


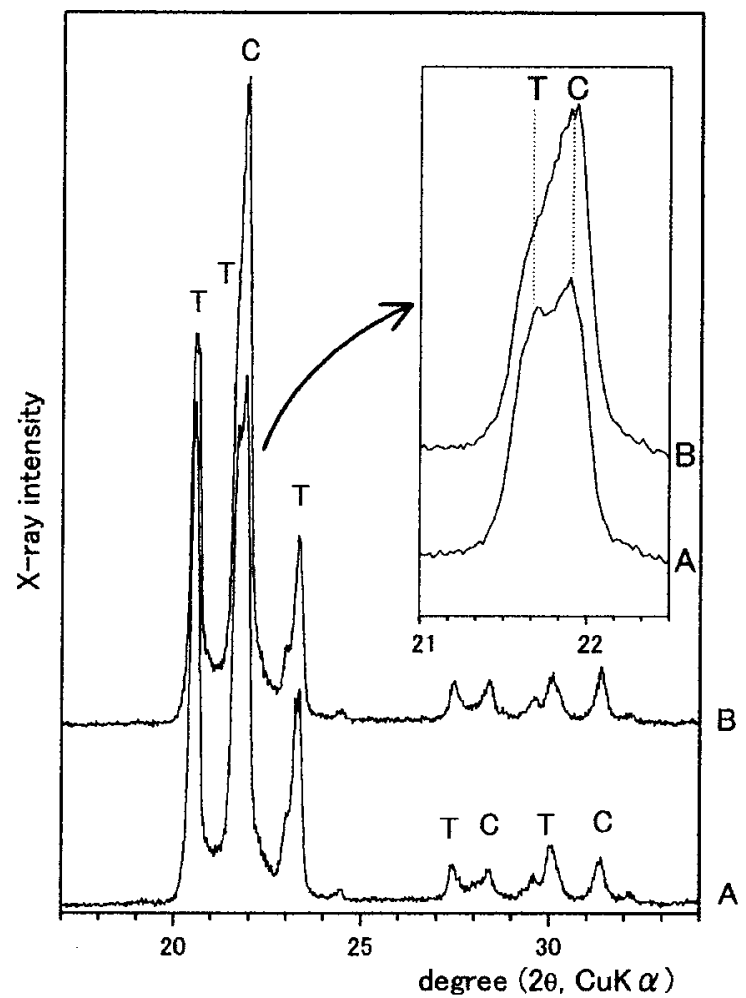

Fig. 3. X-ray diffraction patterns of $A$ ) finely ground and B) gently pulverized rice husk ash samples after heating at $1,200^{\circ} \mathrm{C}$ for $24 \mathrm{~h}$. Symbols $\mathrm{C}$ and $\mathrm{T}$ : peak position of cristobalite and tridymite, respectively.

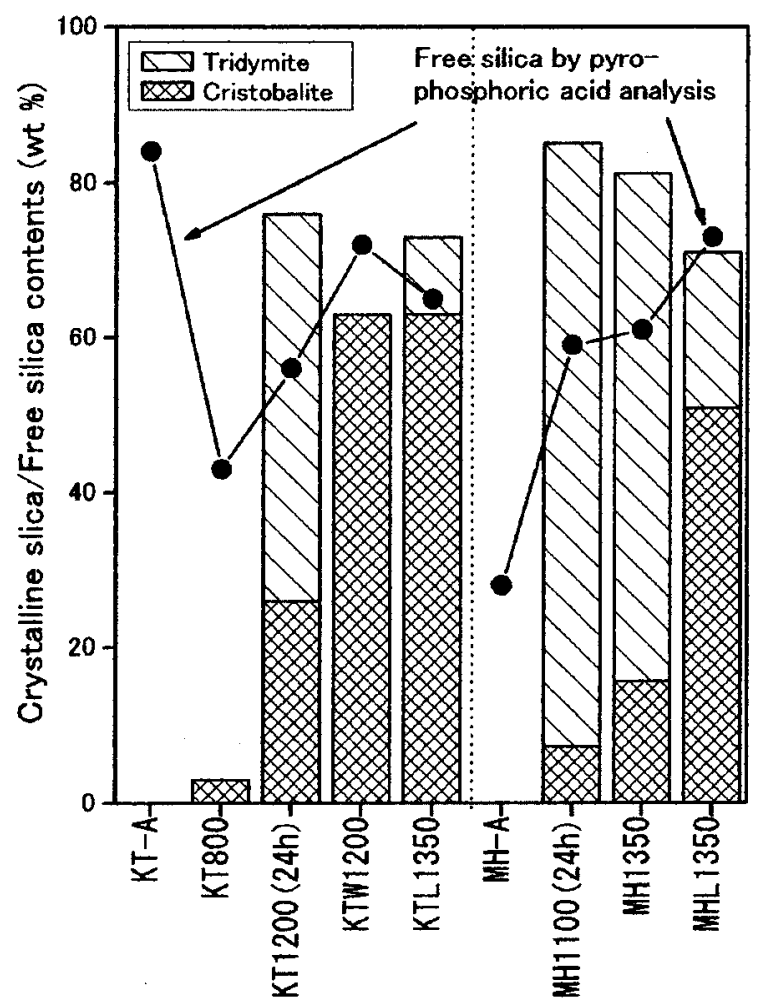

Fig. 4. Comparison of silica contents in rice husk ash samples determined by pyrophosphoric acid analysis (free silica) and by $\mathrm{X}$ ray diffraction analysis (total crystalline silica).

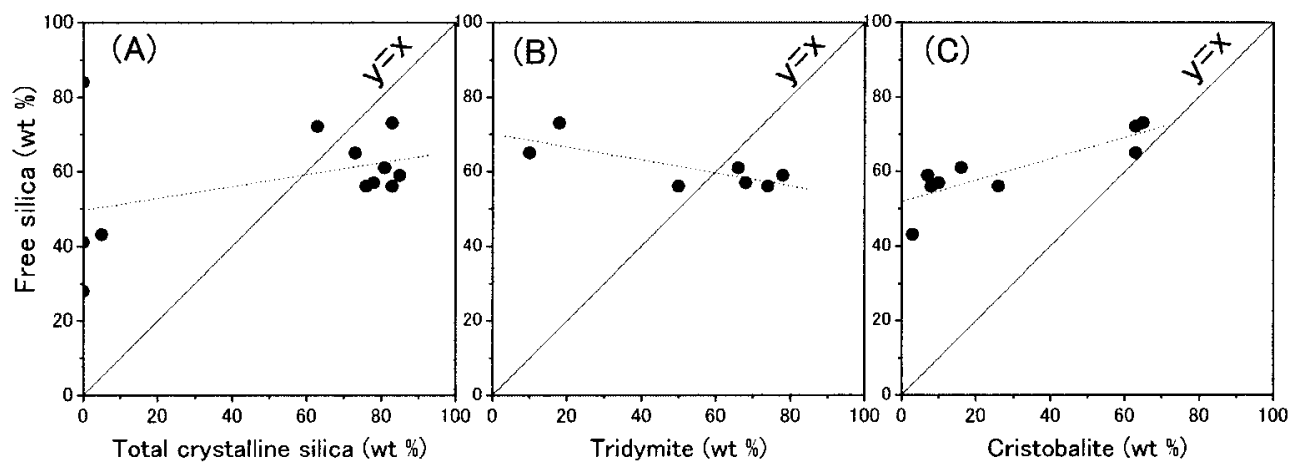

Fig. 5. The relationship between the free silica content obtained by prophosphoric acid analysis and A) cristobalite content, B) tridymite content, and C) total silica contents obtained by X-ray diffraction analysis in rice husk ash samples.

tridymite and cristobalite contents determined by XRD analysis. The recoveries of standard materials of tridymite (TY-27) and cristobalite (SRM1879) were 79\% (or 63\% when a $50 \mathrm{mg}$ sample was employed) and $83 \%$, respectively, by the pyrophosphoric acid analysis (Table 3). Although these two forms of crystalline silica showed a fairly high dissolution in hot pyrophosphoric acid, no corrections for these recovery ratios were done on the values in Table 3. For the two RHA samples (MH-A and KT-A), pyrophosphoric acid analysis gave the free silica contents as $28 \%$ and $84 \%$, respectively, although these two RHA samples consist of almost all amorphous silica. The XRD analysis of the residue, which was obtained by another pyrophosphoric acid dissolution, showed the presence of silicon phosphates such as $\mathrm{Si}_{3}(\mathrm{PO})_{4}$. 
This demonstrated that the hot pyrophosphoric acid did not completely dissolve the amorphous silica in the RHA samples. Figure 5 shows that the values of the free silica content obtained by pyrophosphoric acid analysis did not coincide well with those of the total crystalline silica content obtained by XRD analysis (Fig. 5-A). Furthermore, it was observed that the higher the content of tridymite in heated RHA samples, the lower the content of free silica (Fig. 5B). When the cristobalite content was high in the heated RHA samples, the free silica content was in fairly good agreement with the total crystalline silica content obtained by XRD analysis (Fig. 5-C).

\section{Discussion}

The present study revealed the quantities of two forms of crystalline silica in RHA samples formed by heating. The heated RHA samples contained over $60 \%$ crystalline silica above $900^{\circ} \mathrm{C}$ after $6 \mathrm{~h}$ of heating. This crystallization temperature is lower than that previously recognized in crystalline silica, such as cristobalite transformed from pure amorphous silica powder, and coincides with the results in previous papers on heated RHA samples ${ }^{3,6}$ ). It is believed that this lower crystallization temperature was the result of a higher reactivity of the RHA samples due to the small particle size of amorphous silica and the presence of potassium. It has been reported that amorphous silica containing higher concentrations of potassium, such as $9.4 \%^{11)}$ or $39 \%^{9)}$ as $\mathrm{K}_{2} \mathrm{O}$, is favored for the major crystallization of tridymite at $800^{\circ} \mathrm{C}$. The heated RHA sample (MH-A), which contains about $3 \% \mathrm{~K}_{2} \mathrm{O}$, showed that tridymite was the dominant crystalline phase above $1,000^{\circ} \mathrm{C}$ (for $24 \mathrm{~h}$ of heating ) or $1,100^{\circ} \mathrm{C}$ (for $6 \mathrm{~h}$ of heating). On the other hand, as shown in the leached RHA samples, low potassium RHA samples crystallized to cristobalite as the dominant phase after heating at higher temperatures. These results coincide well with a previous study on the transformation of amorphous silica to crystalline silica in the presence of fairly low concentrations of $\mathrm{K}_{2} \mathrm{O}$ (under $7.0 \%)^{10)}$.

A higher proportion of tridymite is crystallized in one heated RHA sample (MH-A) at a relatively low temperature around $1,000^{\circ} \mathrm{C}$ compared with the other heated RHA samples (KT-A). One reason for this difference is due to the different content of $\mathrm{K}_{2} \mathrm{O}$. Another explanation might be given by considering the distribution of elements in these RHA sample. It is known that silicon is localized in the tough outer layer of rice husk ${ }^{19)}$, whereas the localization of potassium is unknown. It shoud be considered, therefore, that the distribution of silicon and potassium is not closely related to each other in RHA prior to mixing process such as grinding. The heating experiment of well ground KT-A resulted in a high tridymite content. In the finely ground sample, silica and potassium might be mixed well and homogenized. This condition seemed to accelerate the crystallization of tridymite. Since the $\mathrm{MH}$ charcoaled rice husk sample was obtained in the form of a fine powder, the silica and potassium in MH-A was likely mixed well compared with KT-A. Thus, the dominant crystallization of tridymite in heated $\mathrm{MH}-\mathrm{A}$ can be expected by analogy from the results of the grinding experiment of KT-A. In conclusion, a high concentration of potassium and thorough grinding of the RHA sample before heating contribute to the dominant crystallization of tridymite in heated RHA sample.

The development of tridymite standard material and the analytical procedure has not been satisfactory attained partly due to the complex polymorphism of tridymite itself. At room temperature, tridymite exists as monoclinic or psudoorthorhombic structure trypes ${ }^{1}$. The monoclinic structure is common in synthetic tridymite and would be found mostly in workplaces. However, modification of the monoclinic structure by grinding of tridymite is also known ${ }^{20)}$. This modification probably occurs even during the sample preparation procedure and results in affecting the relative intensity relation among the three main peaks of tridymite at $20.5,21.6$ and $23.3^{\circ}$ in XRD. For the quantitative analysis of tridymite, therefore, the following points are important to obtain reliable result: the identification of the structure type, the preparation or selection of standard material having the same structure type, and caution regarding the sample preparation method. In this study, tridymite in heated RHA samples was identified as monoclinic structure and the intensity relationship of the three main peaks was judged to be almost the same as that of the standard tridymite TY-27, which has a monoclinic structure.

The XRD pattern of cristobalite crystallized in heated RHA samples (Fig. 1-C and 1-G) has a feature in which the cristobalite peaks are broad compared with well-crystallized cristobalite such as SRM 1879. This type of cristobalite has been called disordered cristobalite ${ }^{21)}$ and opal- $\mathrm{C}^{22,23)}$. The XRD patterns of some opal-C and disordered cristobalite silicas are similar to each other, such as the peak position and peak width of the strongest peak ${ }^{21}$. Some researchers considered that any forms of opal are not crystalline silica ${ }^{24,25}$. Because opal-C is considered to be transformed from other forms of opaline silica at lower temperatures in nature, disordered cristobalite is an appropriate term to describe this type of 
cristobalite in heated RHA samples. However the degree of disorder in cristobalite is difficult to define, we have to evaluate the amounts of cristobalite phase in the heated RHA samples with reference to well-crystallized cristobalite.

Pyrophosphoric acid analysis may be useful for samples containing mainly quartz as crystalline silica, since the dissolution of quartz can be controlled within a few percent loss. Under the same conditions, however, the dissolutions of tridymite and cristobalite were much greater than that of quartz. Miles $(1994)^{26)}$ reported that the recovery of tridymite (TY-27) was $45.2 \%$ and that of cristobalite (SRM 1879) was $81.6 \%$ by the NIOSH 7601 method $^{27)}$ with a $50 \mathrm{mg}$ sample. The recovery of TY-27 obtained in this study had a somewhat broad range (79-63\%) due to the difference in the amount of sample used in the analysis. It should be noted that the result obtained in present pyrophosphoric acid analysis showed the same lower recovery of tridymite than that of cristobalite and corresponds to the conventional hot phosphoric acid analysis. The differences, then, in the results between the pyrophosphoric acid and XRD analyses must be specific to the RHA sample. The presence of silicon phosphates residue after pyrophosphoric acid dissolution was confirmed by XRD analysis. This residual compound might be formed by the reaction between the amorphous silica in the RHA sample and pyrophosphoric acid and would give positive error in the final result. Since the contents of crystalline and amorphous silica are different in each sample, it would be difficult to evaluate a negative error caused by the dissolution of tridymite and cristobalite and a positive error caused by the formation of silicon phosphate. For the analysis of samples containing any RHA, therefore, it may be concluded that pyrophosphoric acid analysis is not adequate for the evaluation of the total content of crystalline silica.

Rice husk has been considered a suitable energy and silica resource in Asian countries. The occurrence of crystalline silica was recognized in combusted samples of rice husk in Southeast Asian countries. According to Hara $(1988)^{8)}$, both cristobalite and tridymite were identified in some RHA samples obtained from the open-field burning of rice husk, and cristobalite was found in the residual ash of a power generation plant using rice husk as fuel. The XRD pattern of the RHA sample obtained from the open-field burning of rice husk ${ }^{8}$ shows similar patterns to that of the heated RHA sample obtained at $1,000^{\circ} \mathrm{C}$ for $6 \mathrm{~h}$ (Fig. 1 -H). Temperature is an important factor for the crystallization of silica in RHA. It was mentioned that temperatures near $1,100^{\circ} \mathrm{C}$ could be reached inside of heaped rice husk during open-field burning ${ }^{8)}$. Temperature around $800-1,000^{\circ} \mathrm{C}$ can also be attained in fluidized bed reactors, which are often used for the production of $\mathrm{RHA}^{5}$. These temperatures in the uncontrolled burning of rice husk should lead to the crystallization of tridymite in some RHA products.

A case study on the occurrence of pneumoconiosis in the workers of a RHA production factory was reported by Chinese researchers ${ }^{13)}$. They examined the settled dust in the factory by a pyrophosphoric acid analysis and reported $72.3 \%$ free silica content. Although the presence of crystalline silica in the settled dust is uncertain, they estimated in a laboratory experiment that heated RHA samples contained $16-38 \%$ cristobalite and $1.3-6.1 \%$ tridymite based on XRD analysis. The disagreement of their reported results between the pyrophosphoric acid and XRD analyses might be explained by the results reported in this study, i.e. pyrophosphoric acid analysis shows a certain amount of free silica to amorphous silica and can not give an exact result for tridymite and cristobalite contents in an RHA sample.

The study on a substantial feature of the occurrence of RHA dust containing crystalline silica in the workplace is left for future research. A study on Malaysian rice millers indicated the possibility of early silicosis due to the silica in rice husk ${ }^{28)}$. This study suggests the importance of a detailed characterization of the silica in rice husk and in RHA dust to clarify the cause of symptoms. Based on the results obtained in this study and with some information in the literature, we conclude that the analysis of the crystalline silica content in airborne dust is important in preventing pneumoconiosis in workers in RHA production factories, in power generation plants using rice hull, and engaged in farming operations that include the burning of rice husk. For the analysis of crystalline silica in RHA samples, XRD is recommended as a reliable technique for the evaluation of silica content instead of the pyrophosphoric acid method.

\section{References}

1) Heaney PJ (1994) Structure and chemistry of the lowpressure silica polymorphs. In: Silica (Reviews in Mineralogy Vol. 29). eds. by Heaney PJ, Prewitt CT, Gibbs GV, 1-40, Mineralogical Soc Am, Washington, D.C.

2) Eitel W (1957) Structural anomalies in tridymite and cristobalite. Am Ceram Soc Bull 36, 142-8.

3) Nakata Y, Suzuki M, Okutani T, Kikuchi M, Akiyama $\mathrm{T}$ (1989) Preparation and properties of $\mathrm{SiO}_{2}$ from rice hulls. J Ceram Soc Japan 97, 842-9 (in Japanese).

4) Amick JA (1982) Purification of rice hulls as a source of solar grade silicon for solar cells. J Electrochem Soc 
129, 864-6.

5) Okutani T, Nakata Y (1996) Industrial utilization of silica in rice hulls. Netsu Sokutei (Calorimetry and Thermal Analysis) 23, 117-27 (in Japanese).

6) Real C, Alcala MC, Criado JM (1996) Preparation of silica from rice husks. J Am Ceram Soc 79, 2012-6.

7) Juliano BO (1985) Rice hull and rice straw. In: Rice: Chemistry and Technology. eds. by Juliano BO, 2nd ed., 689-755, Am Assoc Cereal Chemists, Minnesota.

8) Hara N (1988) Utilization of rice husk ash for calcium silicate lightweight building materials, J Miner Soc Japan 18, 405-15 (in Japanese).

9) Tomita K, Kawano M (1992) Effect of cations on crystallization of amorphous silica (part 1). Rep Fac Sci Kagoshima Univ (Earth Sci \& Biol) 25, 1-18.

10) Higuchi M, Azuma $Y$ (1997) Effect of alkali metal oxide addition on crystallization and phase transformation of sintered spherical silica. J Ceram Soc Japan 105, 385-90 (in Japanese).

11) Venezia AM, Parola VLa, Longo A, Martorana A (2001) Effect of alkali ions on the amorphous to crystalline phase transition of silica. J Solid State Chem 161, 3738.

12) Rue B, Sakamura H, Yasui I (1993) Thermal and dielectric properties of silica/glass composites with the controlled amount of tridymite. J Ceram Soc Japan 101, 579-82 (in Japanese).

13) Liu S, Liu N, Li J (1996) Silicosis caused by rice husk ashes. J Occup Health 38, 57-62.

14) Kohyama N (1985) A new X-ray diffraction method for the quantitative analysis of free silica in the airborne dust in working environment. Ind Health 23, 221-34.

15) Graf J, Ase P, Draftz R (1979) Preparation and characterization of analytical reference minerals. (National Institute of Occupational Safty and Health (NIOSH) technical report 79-139) 221, NIOSH, Cincinnati.

16) Copeland LE, Bragg RH (1958) Quantitative x-ray diffraction analysis. Anal Chem 30, 196-201.

17) Karlak RF, Burnett DS (1966) Quantitative phase analysis by x-ray diffraction. Anal Chem 38, 1741-5.

18) Shinohara $Y$ (1993) Application of the microwave acid digestion technique to the pyrophosphoric acid method for quantitative analysis of free silica in dust. Ind Health 31, 91-100.

19) Sharma NK, Williams WS, Zangvil A (1984) Formation and structure of silicon carbide whiskers from rice hulls. J Am Ceram Soc 67, 715-20.

20) Xiao Y, Kirkpatrick RJ, Kim YJ (1995) Investigations of MX-1 tridymite by ${ }^{29}$ Si MAS NMR-Modulated structures and structural phase transitions. Phys Chem Minerals 22, 30-40.

21) Graetsch H, Gies H, Topalović I (1994) NMR, XRD and IR study on microcrystalline opals. Phys Chem Mineral 21, 166-75.

22) Jones JB, Segnit ER (1971) The nature of opal 1: nomenclature and constituent phases. J Geol Soc Aust 18, 57-68.

23) Flörke OW, Graetsch H, Martin B, Roller K (1991) Nomenclature of micro-and non-crystalline silica minerals, based on structure and microstructure. Neu J Miner Abh 163, 19-42.

24) Elzea JM, Odom IE, Miles WJ (1994) Distinguishing well ordered opal-CT and opal-C from high temperature cristobalite by x-ray diffraction. Anal Chim Acta 286, 107-16.

25) Smith DK (1998) Opal, cristobalite, and tridymite: noncrystallinity versus crystallinity, nomenclature of the silica minerals and bibliography. Powd Diff 13, 2 19.

26) Miles WJ (1994) Crystalline silica analysis of Wyoming bentonite by $\mathrm{x}$-ray diffraction after phosphoric acid digestion. Anal Chim Acta 286, 97-105.

27) National Institute of Occupational Safty and Health (1984) NIOSH method 7601: Silica, crystalline. In: Manual of analytical methods. eds. by Miller PM, 3rd ed., 84-100 1-5, NIOSH, DHHS Publication, Cincinnati.

28) Lim HH, Domala Z, Joginder S, Lee SH, Lim CS, Abu Bakar CM (1984) Rice miller's syndrome: a preliminary report. Br J Ind Med 41, 445-9. 